\title{
VIVÊNCIA DE EDUCAÇÃO EM SAÚDE: O GRUPO ENQUANTO PROPOSTA DE ATUAÇÃO
}

\author{
EXPERIENCING EDUCATION IN HEALTH:THE GROUP AS A PERFORMANCE PROPOSAL
}

\author{
Rosilda Veríssimo Silva ${ }^{1}$ \\ Priscila Pimentel Costa ${ }^{2}$ \\ Jocemara de Souza Fermino ${ }^{3}$
}

Resumo O texto refere-se a uma experiência de educação em saúde em grupo, realizada em uma unidade de saúde da família na cidade de Joinville, em Santa Catarina, na qual se procurou abordar temas relevantes à saúde daquela população. Tal abordagem foi vivenciada por cinco acadêmicas e uma professora de graduação em Enfermagem da Associação Educacional Luterana Bom Jesus/Ielusc, em 2005. A educação em saúde em grupos permitiu-nos colocar em prática o ensino vivenciado na disciplina de Saúde Coletiva III. O foco principal da atividade visou ao envolvimento e participação de todos os profissionais, as acadêmicas e usuários do sistema de saúde ali presentes com seus saberes e vivências. Abordamos questões relacionadas a diabetes mellitus e hipertensão arterial sistêmica, com ênfase em alimentação. Durante a abordagem, preocupamo-nos em adaptar os materiais e linguagem à realidade dos usuários. A centralidade na atividade partiu das falas dos participantes para discutir mudanças de hábitos, visando melhorar a qualidade de vida. Como reflexões, entendemos que trabalhar com o conhecimento popular e cultura preestabelecida requer cautela, persistência, paciência e motivação do profissional; respeitar os seus saberes e, principalmente, desenvolver a escuta. A oportunidade, para nós, foi a de aprender e ensinar.

Palavras-chave hipertensão arterial sistêmica; diabetes mellitus; enfermagem; educação em saúde.
Abstract The text describes a group experience in education in health carried out in a family health unit in Joinville, state of Santa Catarina, in which an attempt was made to cover issues that were relevant to that population's health. The approach was experienced by five students and an undergraduate professor of Nursing from the Associação Educacional Luterana Bom Jesus/Ielusc, in 2005. Education in health in groups allowed us to put the teaching acquired in the Collective Health III class into practice. The activity focused mainly on getting all of the professionals, the students and the users of the health system present there involved and participating with their knowledge and experience. We approached issues related to diabetes mellitus and systemic arterial hypertension, with emphasis on diet. During the activity, we sought to adapt the materials and the language to the users' reality. The activity began with speeches made by the participants to discuss changes in habit to improve quality of life. As reflections, we believe that working with preestablished popular knowledge and culture requires caution, persistence, patience, and professional motivation; respecting them and, above all, developing listening skills. To us, the opportunity was to learn and to teach.

Keywords systemic arterial hypertension; diabetes mellitus; nursing; education in health. 


\section{A educação em saúde como eixo de trabalho}

O mundo moderno apresenta características que conduzem o ser humano a refletir e atuar na obtenção de qualidade de vida. O termo é subjetivo e ganha importância quando o sujeito o determina sob sua ótica. Sousa (2004) retrata-a a partir de Calman (1984) para quem ela resulta da diferença entre a condição real de vida de uma pessoa e suas expectativas.

Entendemos que a manutenção de hábitos que produzem bem-estar seja ímpar para viabilizar mais autonomia econômica, social e cultural, condições que favorecem a interpretação positiva de qualidade de vida. Sabemos que no caso das doenças crônicas as condições para a prática de atividades físicas, a alimentação equilibrada, as relações ambientais e humanas, além de terapêutica medicamentosa, possibilitam o seu controle, levando os portadores dessas morbidades a adjetivarem-se saudáveis.

Um dos aspectos que parecem significativos nessa qualificação é o controle das doenças crônico-degenerativas não transmissíveis. Conforme Torres, Figueiredo e Waltermann (2006), aí estão incluídas moléstias cardiovasculares, cânceres, diabetes e hipertensão arterial sistêmica, as quais apresentam alta incidência na população mundial. Bahia, Simmer e Oliveira (2004) apontam como fatores determinantes da condição de cronicidade a duração de mais de três meses e o tratamento contínuo ao longo da vida do indivíduo. Assim, neste trabalho, a doença crônica é considerada como aquela que dura mais que três meses e que requer modificações no modo de vida e, algumas vezes, o uso de terapia medicamentosa ao longo da existência da pessoa acometida. Além do mais, são doenças para as quais ainda não existe cura, mas são passíveis de controle.

Dentre essas moléstias, são do âmbito de preocupação os processos patológicos de diabetes mellitus (DM) e hipertensão arterial sistêmica (HAS). No primeiro, incluem-se estados de ausência ou deficiência na produção e/ou ação da insulina; no outro, há elevação dos valores de pressão arterial e, com isso, aumenta o risco de lesão em órgãos como rins, olhos, cérebro e coração.

A estimativa de prevalência de HAS na população brasileira, entre adultos residentes na zona urbana, tem alcançado percentuais entre 15 a $20 \%$. Os fatores relacionados ao aparecimento dessa condição anormal relacionam-se com obesidade, sedentarismo, consumo de álcool e sal elevados e estresse, além de idade. Trata-se de uma doença multifatorial que implica alterações dos mecanismos renais de retenção de sódio, nos sistemas reninaangiotensina e nervoso simpático, além da membrana celular. A morbidade causa modificações estruturais nos vasos sangüíneos, levando-os a processos ateroscleróticos, os quais contribuem para o aumento dos valores da pressão arterial (Cintra et al., 2006; Lima, Hatagima e Silva, 2007). 
De acordo com a Sociedade Brasileira de Hipertensão (2006), os valores considerados dentro da normalidade estão delimitados para a pressão sistólica, não ultrapassando $135 \mathrm{mmHg}$, e para a diastólica, $85 \mathrm{mmHg}$. Para as pessoas com DM, os valores para a pressão sistólica são considerados como objetivo do tratamento, não ultrapassando $130 \mathrm{mmHg}$, e para a diastólica, $80 \mathrm{mmHg}$, conforme a Sociedade Brasileira de Diabetes (2007).

No caso do diabetes ocorrem alterações na membrana interna dos vasos. A pessoa pode apresentar feridas com cicatrização lenta, polidipsia, polifagia e poliúria, necessitando levantar várias vezes no período noturno para o esvaziamento vesical. A doença produz, ao longo do tempo, complicações macrovasculares, neuropáticas e microvasculares. Um dos resultados dessas alterações é o desenvolvimento de lesão nos pés, a qual pode evoluir para amputação do membro afetado. O acometimento de pequenos vasos pode resultar em retinopatia, neuropatia e nefropatia diabéticas (Wajchenberg et al., 2008).

A diabetes tipo 1 ocorre mais em crianças e adolescentes. Nessa condição, o pâncreas não produz insulina, o hormônio responsável pela manutenção do equilíbrio das concentrações de glicose sangüíneas, especialmente após as refeições. Assim, a pessoa acometida necessita receber insulina exógena para atender às necessidades corpóreas. Por sua vez, o diabetes tipo 2 ocorre freqüentemente em adultos obesos, embora as modificações no estilo de vida e alimentação modernos tenham resultado em sua ocorrência na infância (Gabbay, Cesarini e Dib, 2003). Nesses casos, há células beta pancreáticas funcionantes e a manutenção dos níveis glicêmicos é feita inicialmente com o controle dietético e a realização de atividade física. Algumas vezes, essas modificações não surtem os efeitos esperados e passase então ao uso de hipoglicemiantes orais. Diante da não obtenção de resultados glicêmicos aceitáveis com essas medidas, inicia-se o uso de insulina exógena. Melo (2006) relata as vantagens de se iniciar precocemente a insulinoterapia para as pessoas com diabetes tipo 2 , uma vez que implica no retardamento de complicações.

Como se pode notar pelo constitutivo dessas afecções, elas são isoladamente devastadoras. Vale acrescentar que esse efeito fica potencializado na condição de existência delas concomitantemente. Concordamos com Lyra et al. (2006), ao afirmarem que essas características multifatoriais e globais incidem em redução da quantidade em anos e qualidade de vida.

No que se refere ao controle de glicemia capilar, a Sociedade Brasileira de Diabetes (2007) tem como padronização dos valores considerados normais para o hemoglicoteste (HGT): em jejum de 70 a $99 \mathrm{mg} / \mathrm{dl}$, pós-prandial (duas horas) até $140 \mathrm{mg} / \mathrm{dl}$. Para esse grupo de estudiosos, os valores, a qualquer hora do dia que ultrapassem $200 \mathrm{mg} / \mathrm{dl}$, são considerados anormais. No âmbito do cuidado, a meta da terapêutica para pessoas com 
diabetes é alcançar níveis normais de glicose sangüínea, sem romper bruscamente com o estilo de vida e as atividades usuais.

Vale lembrar que ambas são afecções silenciosas, isto é, as alterações vão progredindo sem a manifestação de sinais e sintomas. Normalmente são diagnosticadas quando já há importantes modificações no organismo. Outrossim, são moléstias previsíveis quanto ao surgimento e, em alguns casos, controláveis, permitindo que as pessoas acometidas possam ter qualidade de vida e menores possibilidades de complicações e redução da gravidade. Portanto, são processos que podem se desenvolver ao longo da vida do sujeito e surgirem, ano a ano, mais pessoas em diferentes graus de morbidade, tornando-se um problema de saúde pública. As ações, nesse âmbito, incluem mudanças no estilo de vida e tratamento farmacológico, entre outros, e a educação em saúde torna-se ferramenta para o ensino às pessoas e seus familiares, viabilizando a socialização de informações e orientações.

Percebemos que as sociedades de especialistas têm reduzido os valores dos testes e das aferições, o que, por si só, pode trazer um incremento no número de pessoas que sejam consideradas com maior possibilidade de desenvolver as doenças. Por outro lado, inserem-se nos núcleos de atenção dos profissionais de saúde, no que tange ao desenvolvimento de atividades de acompanhamento e prevenção de agravos e novos casos, bem como a promoção da saúde.

Uma das ferramentas para o enfrentamento dessas condições é a educação e o cuidado desenvolvido em grupo. Trata-se de uma perspectiva no atendimento às pessoas que viabiliza a troca de experiências no intuito de promover aprendizagem, respeitando a cultura e a história dos participantes.

Refletindo sobre a importância de trabalhar a educação em saúde e tendo como base os estudos relacionados sobre diabetes mellitus e a hipertensão arterial sistêmica, doenças que se encontram em local de destaque, acometendo parte da população brasileira, pensou-se a possibilidade de abordar estes temas junto à comunidade. Para isso, e partindo do conhecimento da própria população, debatemos a importância de hábitos alimentares saudáveis e a prática regular de atividade física como ações diretamente ligadas à prevenção dessas doenças e de seus agravos. Essas colocações subsidiaram o desenvolvimento do ensino-aprendizagem que ora abordamos.

Enquanto vivenciávamos o ensino teórico-prático da disciplina de Saúde Coletiva III em uma unidade de saúde da família (USF), tivemos a oportunidade de experienciar o processo educativo por meio da vivência grupal. Essa perspectiva evidenciou-se como abordagem de ensino-aprendizagem de mão dupla: enquanto debatíamos com os participantes, com o objetivo de sensibilizá-los, estávamos colocando em prática as teorias estudadas em sala de aula também entre docente e estudantes. Esses foram os 
fatores que nos motivaram a divulgar nossa experiência de educação em saúde com pessoas com hipertensão arterial e diabetes mellitus.

Entendemos a educação em saúde que foge da exclusividade preventivo-curativa como proposta que possibilita, a cada sujeito, comprometer-se com as ações que visam ao seu bem-estar e ao melhor viver.

A vivência grupal, como abordagem à prática de trocas de experiências, ouvir o outro, conhecer o contexto de cada participante, vem complementar, de modo enriquecedor, o campo da educação em saúde.

O planejamento para a realização da atividade em grupo é apresentado em categorias operativas que cobrem quatro campos: ensino-aprendizagem, institucionais, comunitários e terapêuticos. A categoria terapêutica visa, fundamentalmente, a uma melhoria de algumas situações que envolvam patologias dos indivíduos. As formas mais utilizadas dessas modalidades grupais são conhecidas como grupo de auto-ajuda ou ainda mútua ajuda, formadas por pessoas que apresentam interesses em comum ou características semelhantes entre si e aderem a esse subgrupo de atenção primária com suporte preventivo de promoção à saúde (Zimerman e Ozório, 1997).

A possibilidade de atuar na promoção de saúde diante desses aspectos nos pareceu intervenção necessária ao se pensar na autonomia, responsabilidade e parceria com as pessoas do bairro.

\section{A vivência de educação em grupo}

Durante o ensino teórico-prático realizado em uma unidade de saúde da família (USF) em Joinville, no estado de Santa Catarina, propusemos à enfermeira da unidade o desenvolvimento de grupos de educação em saúde para a comunidade. Fomos responsabilizadas por organizar três encontros. Nesse trabalho, destacamos nossa experiência com o tema alimentação saudável para pessoas com diabetes mellitus e hipertensão arterial.

O objetivo de abordar o tema foi, especialmente, tentar articular o conhecimento daquela população a aspectos que visavam a melhorar a qualidade de vida e prevenir agravos relacionados a estas duas patologias. Para tanto, planejamos destacar os hábitos de vida saudáveis, relacionados à alimentação, sem, entretanto, trazer tais informações sob a forma de palestras, as quais permitem pouca ou nenhuma participação ativa dos membros do grupo.

Desenvolvemos esta atividade nas datas previamente agendadas pela enfermeira com o grupo de pessoas portadoras de diabetes e hipertensão pertencentes à área de abrangência da unidade. Assim, os envolvidos não teriam que alterar suas dinâmicas pessoais para comparecer ao local, pois era uma proposta acertada com eles. Participaram da atividade 25 usuários. 
Conforme as orientações da equipe de saúde local, tratava-se de uma população com menor acesso ao ensino formal e cujas condições econômico-financeiras permitiam o consumo de alimentos e produtos básicos para a sobrevivência, entre eles o macarrão, a batata, o feijão, o arroz, o óleo, o café e o açúcar.

O nosso grupo de estudantes era formado por cinco acadêmicas, todas cursando o terceiro período do Curso de Graduação em Enfermagem da Associação Educacional Luterana Bom Jesus/Ielusc.

Antes do desenvolvimento da atividade realizaram-se reuniões, sob orientação da professora, nas quais foram discutidas a fisiopatologia, tratamento medicamentoso da diabetes mellitus e hipertensão arterial e suas complicações. Também foi solicitado e discutido, ao longo do preparo da atividade, o tema educação em saúde, em especial 'grupo', as diferentes funções desempenhadas pelos participantes, bem como a mediação feita pelo coordenador.

A partir do conteúdo acima estudado foi realizada a divisão de tarefas entre as acadêmicas, que consistia em: previsão da quantidade de participantes, material e tempo necessário para um bom aproveitamento da atividade, bem como a duração e o método de encerramento a ser utilizado.

Quanto aos hábitos saudáveis de alimentação, optamos por trabalhar de forma lúdica para maior entrosamento e descontração dos participantes. Este método, como afirma Sousa (2004), é importante para o estabelecimento de comunicação simples com as pessoas sem, entretanto, infantilizá-las. Programamos o tempo disponível em quatro etapas: na primeira, fizemos um teatro de fantoches, elaborado pela docente e pelo grupo de acadêmicas; na segunda, preparamos os cartazes com figuras de alimentos; na terceira, discutimos as opções individuais, abrindo o debate para o grande grupo; e, na quarta, o encerramento, com um convite a todos para a realização de alongamento.

No dia do encontro, chegamos mais cedo à unidade com o objetivo de preparar a sala e os materiais que seriam utilizados. Enquanto algumas alunas se preparavam para o teatro, outras recepcionavam os participantes. Esperavam-se, aproximadamente, trinta pessoas, visto que a unidade costuma convidá-las conforme a microárea na qual residem. Diante disso, a fim de obter uma melhor prática da escuta, optamos por distribuí-los em subgrupos. Para a elaboração dos cartazes, no primeiro encontro dividimos o grande grupo em quatro subgrupos de três integrantes, e cinco no segundo encontro, com o intuito de facilitar a nossa organização com o trabalho desenvolvido. Cada subgrupo foi coordenado por duas estudantes. Sabemos, entretanto, que este não é o número ideal para trabalhar com grupo quando o objetivo está direcionado a mudanças comportamentais. Segundo Said (2001), em dinâmicas pedagógicas para práticas educativas na saúde de dia- 
béticos e hipertensos, o ideal seria trabalhar com um grupo composto de, no máximo, vinte pessoas.

Compareceram 12 pessoas na primeira reunião e 15 na segunda, atingindo um número satisfatório para o desenvolvimento da atividade. Porém, como forma de ajuste, optamos pela manutenção da reorganização em subgrupos.

Quando a maior parte dos convidados já se encontrava na unidade e, conforme o horário acordado, iniciamos as atividades com a verificação da pressão arterial e realização do hemoglicoteste, seguindo as orientações da enfermeira da unidade. Nesta etapa, os valores eram transcritos no cartão individual de cada participante e registrados nos respectivos prontuários. Em seguida, convidamos a todos para que se colocassem em forma de semicírculo em frente ao palco.

O teatro teve início com a amostra de frutas e verduras in natura antes da apresentação das personagens. A exposição de alimentos naturais teve como objetivo familiarizar os participantes com a temática.

Criamos uma história na qual havia quatro personagens, duas tinham vivenciado experiências com a doença e as outras duas representavam uma espécie de 'consciência', as quais protagonizavam 'o informado' e o 'não tão informado'. Por meio de linguagem simples, as personagens recordavam o valor nutricional de cada alimento, sua importância e ainda quantidades a serem consumidas em especial por portadores de diabetes e hipertensão. Durante o decorrer da dinâmica teatral, pôde-se observar o interesse e a identificação da platéia com o contexto vivido pelas personagens, através das expressões faciais e dos comentários, apontando e identificando os alimentos expostos.

Na etapa seguinte, confeccionamos cartazes em parceria com os participantes do grupo educativo. Cabe ressaltar que o preparo de materiais que subsidiou esse momento foi elaborado a partir das informações da equipe da unidade de saúde sobre a realidade financeira e cultural dos participantes, e, a partir daí, decidiu-se pela utilização de figuras de alimentos que foram recortados de jornais promocionais e revistas. A escolha desses alimentos teve por base um cardápio fornecido pela enfermeira da unidade, no intuito de dar continuidade às suas orientações. Assim, abordamos o uso de alimentos como: arroz, feijão, macarrão, pães, carnes, verduras, legumes, frutas, leguminosas, derivados de leite, ovos e guloseimas como chocolates, refrigerantes, bolos, bolachas, entre outros.

Queríamos perceber com essa dinâmica o entendimento dos participantes, pois o conhecimento de cada indivíduo pode enriquecer e fortalecer o grupo por meio de uma troca de saberes. Assim, experienciamos a etapa que objetivava afixar em cartazes recortes dos alimentos mais consumidos individualmente. Com o objetivo de estimulá-los, as coordenadoras 
reafirmavam verbalmente com cada sujeito a escolha e a identificação das figuras, para, na seqüência, serem coladas nos cartazes. Cada coordenadora ficou responsável, também, por agrupar falas que oportunizariam aquecer e iniciar o debate.

A partir de cada cartaz voltou-se à discussão no grande grupo, utilizando-se das experiências dos usuários para sanar dúvidas e sugestões de uma dieta, quanto à qualidade e quantidade de alimento a ser consumido. A ênfase também foi feita em relação à necessidade do gasto das calorias consumidas com a prática de atividades, como caminhadas. Outro aspecto importante abordado para melhor a manutenção das condições saudáveis de vida envolveu a redução do uso de sal, café, gorduras, doces, massas, fumo e álcool, bem como a importância da ingestão hídrica.

No encerramento, solicitamos aos usuários suas opiniões em relação ao trabalho realizado e destacamos algumas palavras-chave de suas falas: 'interessante', 'proveitoso', 'legal', 'fácil para entender', 'diferente', entre outras. Essa maneira de trazer o tema foi dinâmica e todos se sentiram à vontade para verbalizar, demonstrando entendimento do assunto em pauta. Finalizamos a atividade usando uma técnica de alongamento, com o objetivo de incentivá-los à prática de atividades físicas e também como um modo alternativo e descontraído para o fechamento do encontro.

\section{O desafio: a ótica das organizadoras sobre a atividade grupal}

Desenvolver grupos de educação em saúde significou, para nós, mais que uma simples atividade, tornou-se um desafio, pois não tínhamos domínio teórico-científico dos temas trabalhados, uma vez que o currículo do curso prevê o estudo da clínica a partir da quarta fase. Ainda que esse conteúdo não houvesse sido estudado em disciplinas anteriores, buscamos, na literatura específica, aperfeiçoar nossos conhecimentos. Sabíamos que essa experiência representaria um acréscimo positivo para nossa vivência enquanto acadêmicas.

No que diz respeito à organização dessa atividade, cabia-nos a responsabilidade pela prática e pela busca da reciprocidade dos participantes. Afinal, nós, como acadêmicas, não tínhamos até o momento nenhuma convivência com os integrantes do grupo. A coordenação do tempo disponível e estabelecido causou-nos inquietação, já que era o primeiro contato com esse tipo de organização grupal. No entanto, no decorrer da atividade os participantes demonstraram grande interesse nos temas propostos.

A integração entre os membros do grupo e a participação nas atividades realizadas fizeram-nos perceber a importância de trabalhar grupos de educação para saúde, acreditando na eficácia desse trabalho. Apesar de não 
obter resultado imediato, a educação em grupo possibilita ao profissional desenvolver integração com os participantes ao estabelecer confiança, principalmente no que está sendo proposto, uma vez que trabalhar com o conhecimento popular e cultura preestabelecida requer cautela, persistência, paciência e motivação do profissional. Ao longo de nossas abordagens, a partir do diálogo ouvimos os participantes em suas crenças para elaboramos o elo com o conhecimento acadêmico. Assim, a troca de saberes ocorreu tranqüilamente.

Também se configurou desafio lidar com a ansiedade no planejamento da ação. O semblante de algumas estudantes levou-nos a racionalizar que o não entendimento integral da proposta a ser desenvolvida poderia nos furtar do alcance dos objetivos junto ao grupo de usuários. Diante disso, em muitas ocasiões, foram debatidas e esclarecidas as idéias e estudos.

Por outro lado, compreendíamos na prática dessa vivência com os usuários do sistema de saúde local o que entendem por saúde, doença e qualidade de vida. No âmbito da profissionalidade da enfermeira, tal conduta dimensiona que ela possa conduzir esse tipo de atividade com a população de modo a respeitar os seus saberes e, principalmente, desenvolver a escuta, que condiciona o sucesso dessa forma de trabalho. Isso estimulou a construção e reconstrução do conhecimento técnico-científico e da lógica da educação em saúde na interação com as estudantes e levou-nos a indicar caminhos e possibilidades. Em outras palavras, ensinou-nos a aprender e a compreender a aprendizagem como um processo heterogêneo. E, ao final da proposta, ficou mais evidente o que Freire (2002) refere quando afirma que, como seres inconclusos, sempre estamos aprendendo a ser e estar no mundo com os outros.

\section{Considerações finais}

A realização deste trabalho criou a oportunidade de uma nova experiência na qual pudemos aprender e ensinar. A busca dos conteúdos a serem utilizados foi de grande importância, pois amadurecemos nossos conhecimentos e opiniões não somente com referência às patologias estudadas, mas também no trabalho em grupo com educação em saúde.

Este trabalho foi aplicado para dois conjuntos de pessoas com diferentes patologias nos quais observamos um desenvolvimento significativo nas acadêmicas de graduação da Associação Educacional Luterana Bom Jesus/Ielusc. Como relata Freire (2002), nessa dinâmica de educar o educador se educa. Assim, experimentamos a condição de eternos aprendizes e de educadores para a vida. 
Após o término de todas as atividades, pedimos para que os participantes resumissem em uma palavra a experiência vivida, e o retorno mostrou-se positivo, com o estabelecimento de um acréscimo em seus conhecimentos, o que, seguramente, contribuirá para uma mudança nos hábitos saudáveis de vida.

\section{Notas}

1 Professora adjunta da Associação Educacional Luterana Bom Jesus/Ielusc. Joinville, Santa Catarina, Brasil. Mestre em Educação pela Universidade Federal de Santa Catarina (UFSC). <roverissimobustus@hotmail.com>

Correspondência: Associação Educacional Luterana Bom Jesus/Ielusc. Rua Princesa Isabel, 438, Centro, Joinville, Santa Catarina, Brasil, CEP 89201-270.

2 Graduanda em Enfermagem pela Universidade do Vale do Itajaí (Univali). < fungono fungo@hotmail.com>.

3 Graduanda em Enfermagem pela Associação Educacional Luterana Bom Jesus/Ielusc. <juce_f@yahoo.com.br>

\section{Referências}

BAHIA, Lígia; SIMMER, Elaine; OLIVEIRA, Daniel Canavese de. Cobertura de planos privados de saúde e doenças crônicas: notas sobre utilização de procedimentos de alto custo. Ciência \& Saúde Coletiva, Rio de Janeiro, v. 9, n. 4, p. 921-929, out./dez. 2004.

BEVILACQUA, Fernando et al. Fisiopatologia clínica. 5. ed. São Paulo: Atheneu, 1998. Cap. 4.

CINTRA, Fátima Dumas et al. Alterações cardiovasculares na síndrome da apnéia obstrutiva do sono. Arquivos Brasileiros de Cardiologia, São Paulo, v. 86, n. 6, p. 399-407, jun. 2006. Disponível em: $<$ www.medsono.com.br/arquivos/Alteraco es_cardiovasculares.pdf $>$. Acesso em: 21 out. 2008.
FREIRE, Paulo. Pedagogia da autonomia: saberes necessários à prática educativa. São Paulo: Paz e Terra, 2002.

GABBAY, Monica; CESARINI, Paulo R.; DIB, Sergio A. Diabetes melito do tipo 2 na infância e adolescência: revisão da literatura. Jornal de Pediatria, Rio de Janeiro, v. 79, n. 3, 2003. Disponível em: <www.scielo.br/pdf/ jped/v79n3/v79n3a04.pdf > . Acesso em: 23 out. 2008 .

LIMA, Sandro Gonçalves de; HATAGIMA, Ana; SILVA, Norma Lucena Cavalcanti L. da. Sistema renina-angiotensina: é possível identificar genes de suscetibilidade à hipertensão? Arquivos Brasileiros Cardiologia, São Paulo, v. 89, n. 6, p.427-33 São Paulo, dez. 2007. Disponível em: $<$ www.scielo.br/scielo.php? pid=S0066- 
782X2007001800013\&script=sci_arttext\&tl $\mathrm{ng}=\mathrm{pt}>$. Acesso em: 21 out. 2008.

LYRA, Ruy et al. Prevenção do diabetes mellitus tipo 2. Arquivos Brasileiros de Endocrinologia e Metabologia, São Paulo, v. 50, n. 2, p. 239-249, abr. 2006. Disponível em: <http://www.scielo.br/pdf/abem/v50n2/29 307.pdf>. Acesso em: 22 out. 2008.

MELO, Karla F. S. de. Como e quando usar insulina no paciente com diabetes mellitus tipo 2: o papel do clínico/cardiologista. Revista Sociedade de Cardiologia do Rio Grande do Sul, n. 8, maio.-jun.-jul-ago., 2006. Disponível em: <www.sabedotti.com.br/ Como \% 20e \% 20quando \% 20iniciar \% 20 com $\%$ 20insulina $\% 20 \mathrm{em} \% 20$ paciente $\%$ 20 com $\% 20$ DM2.pdf $>$. Acesso em: 27 out., 2008 .

MIRANDA, Roberto Dischinger et al. Hipertensão arterial no idoso: peculiaridades na fisiopatologia, no diagnóstico e no tratamento. Revista Brasileira de Hipertensão, São Paulo, v. 9 n. 3, p. 293-300, jul.-set. 2002.

SAID, Fátima Aparecida. Dinâmicas pedagógicas na perspectiva da educação em saúde. Curitiba: Editora do Autor, 2001.

SMELTZER, Suzanne; BARE, Brenda. Histórico e tratamento de pacientes com diabetes mellitus. In: Brunner e Suddarth: tratado de enfermagem médico-cirúrgica. 9. ed. Rio de Janeiro: Guanabara Koogan, 2002. Cap. 37, p. 933-983.
SOUSA, Ana Luiza Lima. Educando a pessoa hipertensa. In: PIERIN, Ângela. $H i-$ pertensão arterial: uma proposta para o cuidar. Barueri: Manole, 2004. Cap. 10, p. 165-184.

SOCIEDADE BRASILEIRA DE DIABETES. Valores de glicemia para o diagnóstico de diabetes. Disponível em: <www.diabetes. org.br/diabetes/exames/valores deglicemia. php>. Acesso em: 5 jan. 2007.

DIRETRIZES BRASILEIRAS DE HIPERTENSÃO, 5, São Paulo, 2006. São Paulo: Sociedade Brasileira de Hipertensão [2006?].

TORRES, Luzia Simone; FIGUEIREDO, Maria Renita Burg; WALTERMANN, Martha. Hipertensão arterial: um desafio para a equipe multiprofissional. Logos: revista de divulgação científica, Universidade Luterana do Brasil, Canoas, v. 1, n. 1, p. 129138, 1. sem., 2006, Especial Enfermagem.

WAJCHENBERG, Bernardo Léo et al. Doença cardiovascular no diabetes melito tipo 1. Arquivos Brasileiros de Endocrinologia e Metabologia. São Paulo, v. 52, n. 2, p. 387-397. Disponível em: < www.scielo.br/ scielo.php?script $=$ sci_arttext $\&$ pid $=S$ $000427302008000200027 \& \operatorname{lng}=\& \mathrm{nrm}=$ iso >. Acesso em: 27 out. 2008.

ZIMERMAN, David E.; OSORIO, Luiz Carlos. Como trabalhamos com grupos. Porto Alegre: Artes Médicas, 1997. cap. 4; cap.7.

Recebido em 18/02/2008

Aprovado em 26/11/2008 
